\title{
Laboreal
}

Volume $14 \mathrm{~N}^{\circ} 1$ | 2018

O regresso ao emprego após um acidente de trabalho

\section{Percursos de regresso ao trabalho após acidente: confronto com novos obstáculos}

Trayectorias de vuelta al trabajo tras un accidente: enfrentarse a nuevos obstáculos

Parcours de retour au travail après un accident: faire face à de nouveaux obstacles

Back-to-work paths after an accident: facing new obstacles

\section{Cláudia Pereira, Marta Santos e Liliana Cunha}

\section{OpenEdition}

Journals

Edição electrónica

URL: http://journals.openedition.org/laboreal/430

DOI: $10.4000 /$ laboreal.430

ISSN: 1646-5237

\section{Editora}

Universidade do Porto

\section{Refêrencia eletrónica}

Cláudia Pereira, Marta Santos e Liliana Cunha, « Percursos de regresso ao trabalho após acidente: confronto com novos obstáculos », Laboreal [Online], Volume $14 \mathrm{~N}^{0} 1$ | 2018, posto online no dia 01 julho 2018, consultado o 09 outubro 2019. URL : http://journals.openedition.org/laboreal/430 ; DOI : 10.4000/laboreal.430

Este documento foi criado de forma automática no dia 9 outubro 2019 


\title{
Percursos de regresso ao trabalho após acidente: confronto com novos obstáculos
}

\author{
Trayectorias de vuelta al trabajo tras un accidente: enfrentarse a nuevos \\ obstáculos \\ Parcours de retour au travail après un accident: faire face à de nouveaux \\ obstacles \\ Back-to-work paths after an accident: facing new obstacles
}

Cláudia Pereira, Marta Santos e Liliana Cunha

\section{NOTA DO EDITOR}

http://dx.doi.org/10.15667/laborealxiv0118cper

Manuscrito recebido em: março/2018

Aceite após peritagem: abril/2018

\section{Direito de regresso ao trabalho após acidente}

1 O acidente de trabalho é um turning point em qualquer percurso profissional, em qualquer idade, para qualquer trabalhador. As dificuldades em reconstruir este percurso são marcadas por diferentes determinantes, situados a vários níveis de análise, como aliás dão conta os textos publicados no âmbito deste dossier.

2 O 'estatuto de trabalhador', a continuidade ou não do vínculo laboral no contexto onde o acidente foi produzido, é muitas vezes abalado por este acontecimento, particularmente quando se traduz em incapacidade para o trabalho, seja este a termo ou sem termo, e requer cuidados médicos. Durante este período, não é raro esse estatuto e os seus direitos serem interpelados, com o prenúncio, infelizmente sempre 
presente, de um requisito de culpa se não pelo acidente, pela não adaptação às condições e exigências do posto de trabalho.

O 'regime infortunístico laboral' (Lei n. 9 98/2009, de 4 de setembro) assegura aos trabalhadores sinistrados direitos ligados à segurança no emprego e à reabilitação profissional, bem como à reparação, não se confinando, pois, a uma função exclusivamente compensatória da redução da capacidade de ganho, mas promovendo também o restabelecimento da capacidade de trabalho e de recuperação para a vida ativa.

Paradoxalmente, este infortúnio é perpetuado, no trabalho e para além dele - pelos 'a priori' de que é objeto o trabalhador aquando do regresso ao trabalho, visto ora como 'reivindicativo', ora como 'dissimulado'. Mas também, como veremos no âmbito dos estudos aqui apresentados, pelo difícil reconhecimento da incapacidade produzida pelo acidente, que também ultrapassa a incapacidade física para o trabalho; pelos critérios de avaliação do trabalho que passa então a ser feito (Dejours, 2003), e que mantêm ausente a referência aos efeitos do acidente; pelas relações no seio do coletivo de trabalho, nomeadamente, pelo julgamento que é feito do trabalhador sinistrado, em função do trabalho que consegue, ou não, fazer (Dejours, 1995).

5 Propomo-nos então a uma análise para além do que a legislação garante em termos de regresso do trabalhador sinistrado à vida ativa, reorientando o olhar para o que se passa em contexto real, no dia-a-dia de trabalho, e de forma contrastada para homens e mulheres, tendo como referência dois estudos desenvolvidos em Portugal: um estudo relativo à análise de percursos profissionais específicos no âmbito de uma empresa do Norte de Portugal; e um outro estudo que assume um ponto de vista mais macro de análise, orientado para a construção de um retrato global dos trabalhadores homens e mulheres, que sofreram um acidente de trabalho em diferentes setores de atividade.

\section{0 acidente de trabalho como um turning point}

6 Analisar os acidentes de trabalho como um turning point, significa considerá-los enquanto momentos de rutura na continuidade de um percurso, tal como este se estava a concretizar, podendo ser assumidos como marcos significativos que existem ao longo da vida (Hareven \& Masaoka, 1988), ou como momentos de interseção entre os vários contextos de vida (Ramos, 2006). Representam 'avaliações' individuais subjetivas das continuidades e descontinuidades das suas vidas, especialmente de acontecimentos que vão ocorrendo com impacto subsequente noutros acontecimentos. Em alguns casos, os turning points são vistos como mudanças críticas, e noutros casos como 'novos começos' (Cohler, 1982, cit por Hareven \& Masaoka, 1988; Masaoka et al., 1985, cit por Hareven \& Masaoka, 1988).

7 Alguns destes momentos de transição (e.g. o início da vida profissional; o nascimento dos filhos) são definidos como normativos se estiverem enquadrados no que tipicamente se define como norma social; no entanto, obviamente, isto não significa que todas as transições sejam normativas. Podem ocorrer em momentos de um percurso em que não são expectáveis, ou de modo imprevisto, criando uma certa dissonância face às normas sociais partilhadas pelos grupos (Hareven \& Masaoka, 1988), como é o caso dos acidentes de trabalho. 
Um turning point não corresponde a um evento isolado, pontual, mas sim a um processo que envolve a alteração do percurso de vida. Assim, trata-se de uma mudança que requer novas escolhas e estratégias (Hareven \& Masaoka, 1988). No caso dos acidentes de trabalho, podemos aludir ao facto de este implicar também, por vezes (e em função da sua gravidade e da incapacidade atribuída), o ajuste ou alteração do posto de trabalho, mudança de função, a reorientação profissional, despedimento após acidente, entre outros.

9 Nem todos os turning points têm impactos de longa duração. Alguns possuem efeitos mais limitados no tempo, e podem não causar alterações significativas nas trajetórias de vida no momento da sua ocorrência. Tal é o caso, por exemplo, de alguns acidentes de trabalho sem atribuição de incapacidade, e cuja lesão não implicou alteração do trabalho realizado ou reorientação profissional, embora isso não signifique que o seu impacto seja limitado na vida dos trabalhadores.

\section{Que percursos resultantes destes turning points?}

10 O impacto de um acidente sobre o percurso profissional tem sido objeto de diversas investigações (Halima \& Regaert, 2015; Baril, Martin, Lapointe \& Massicotte, 1994; Durand, Baril, Loisel \& Gervais, 2008). Estes trabalhos têm, entre outras consequências, alertado para o impacto do acidente na empregabilidade de trabalhadores sinistrados.

11 Nestes estudos, a análise de percursos concretos de regresso ao trabalho pós-acidente permitiu a construção de categorias de trajetórias com características comuns. Assim, no estudo de Baril, Martin, Lapointe e Massicotte (1994), a análise de dossiês de percursos de trabalhadores acidentados, permitiu a constituição de quatro categorias de acordo com o resultado do processo de readaptação: (i) os trabalhadores que retornaram ao antigo empregador; (ii) os trabalhadores que mudaram de empregador; (iii) os trabalhadores que não conseguiram reinserção no mercado de trabalho; e, (iv) os trabalhadores que foram considerados 'inempregáveis'.

No âmbito de um outro estudo, envolvendo alguns dos mesmos investigadores (Durand, Baril, Loisel \& Gervais, 2008), a forma de categorizar os percursos foi enriquecida, sendo as quatro trajetórias possíveis definidas pelo cruzamento de duas variáveis: estatuto de emprego dos participantes (regresso ao trabalho e preservação do vínculo laboral, ou não-regresso ao trabalho, com perda desse vínculo), e a natureza da progressão durante o programa de reabilitação do trabalhador no processo de recuperação pós-acidente (com ou sem obstáculos para a progressão). Na figura 1, ilustra-se graficamente, a modelização das quatro categorias construídas com base na análise de 18 percursos de trabalhadores. 
Figura 1: Diagrama de percursos (adaptado de Durand, Baril, Loisel \& Gervais, 2008)

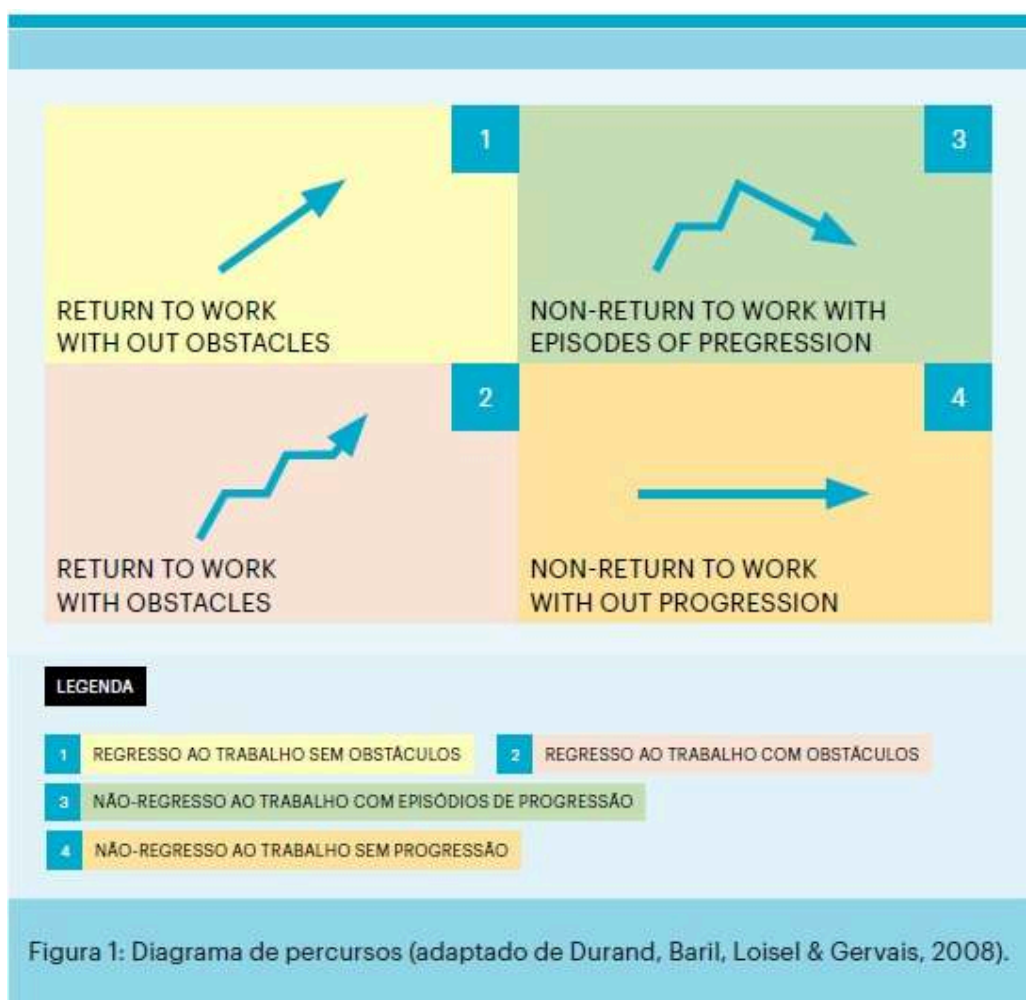

Legenda: (1) Regresso ao trabalho sem obstáculos; (2) Regresso ao trabalho com obstáculos; (3) Não-regresso ao trabalho com episódios de progressão; e (4) Não-regresso ao trabalho sem progressão

Estas categorizações e a sua análise têm permitido identificar um conjunto de fatores que, ora facilitam, ora dificultam a reinserção profissional.

Assim, o facto de se trabalhar em empresas de grandes dimensões, ter a possibilidade de se optar por um horário flexível, e possuir uma longa antiguidade, parecem constituir-se enquanto facilitadores do processo de reinserção após o acidente de trabalho (Baril, Martin, Lapointe, \& Massicotte, 1994; Durand, Baril, Loisel \& Gervais, 2008).

Também foi possível constatar que o regresso ao trabalho é influenciado pelo lapso de tempo entre o acidente e a sua gestão pelo sistema de prestação de cuidados de saúde, pela definição de um diagnóstico médico, e pela história do tratamento (Durand, Baril, Loisel \& Gervais, 2008). Isto é, as múltiplas versões de diagnóstico elaboradas por diversos médicos especialistas, a forma como são atribuídas as restrições funcionais, a ausência de avaliação das capacidades funcionais residuais e a ausência de acompanhamento após o regresso ao trabalho, parecem constituir-se como aspetos que dificultam este percurso pós-acidente (Baril, Martin, Lapointe, \& Massicotte, 1994). No mesmo sentido, os sentimentos de perca de dignidade e autonomia, o desenvolvimento de uma imagem negativa de si, e os 'sentimentos de vergonha associados ao facto de receber e, sobretudo, estar dependente de subsídios para assumir o que os trabalhadores consideram ser as suas responsabilidades sociais e familiares' (Baril, Martin, Lapointe, \& Massicotte, 1994, p.13, tradução livre) são, também, fatores dificultadores do processo de reinserção profissional. 


\section{Reconstrução de percursos pós-acidente: estudos realizados em Portugal}

Os contextos atuais das empresas são marcados, por um lado, pelas evoluções demográficas e pelo prolongamento anunciado da vida ativa e, por outro lado, pela necessidade de aumento da produtividade, associada, por vezes, a mudanças de objetivos ou métodos de trabalho. Esta dupla evolução torna mais delicada a construção de estratégias de reconversão profissional dos trabalhadores, sobretudo no caso daqueles que apresentam restrições de saúde temporárias ou permanentes (Delgoulet, Cuvelier, Gaudart, Molinié, \& Volkoff, 2014).

Apresentamos em seguida uma breve contextualização dos dois estudos desenvolvidos em Portugal e que servem de referência na análise de fatores de constrangimento que marcam, de forma decisiva, os percursos após o acidente.

\subsection{Estudo de caso no setor da logística}

No seguimento do pedido de uma empresa portuguesa do setor da logística para desenvolver e implementar um projeto de reorientação profissional junto de trabalhadores com reconhecida incapacidade para o exercício do trabalho habitual, foi realizada uma intervenção com o propósito de pensar as trajetórias profissionais destes trabalhadores, procurando conciliar as alternativas equacionadas pela empresa com as perspetivas dos trabalhadores relativamente ao seu futuro profissional.

Esta intervenção iniciou-se com um projeto-piloto, dirigido a 20 trabalhadores da empresa ( 12 homens e 8 mulheres, com idades compreendidas entre os 29 e os 52 anos e uma média de 41 anos; e uma antiguidade na empresa entre os 5 e 22 anos, com uma média de 10 anos), com o objetivo de análise do seu percurso profissional e exploração de possíveis alternativas de posto de trabalho compatíveis com a sua restrição, motivações, interesses e competências.

Neste grupo de participantes, os acidentes de trabalho registados correspondem, na sua maioria, a dores súbitas incapacitantes, resultantes da manipulação de cargas pesadas, e das posturas penosas que o trabalho exige. Os tipos de lesões mais frequentes, e decorrentes destes acidentes, correspondem a lesões músculo-esqueléticas (e.g. ombros, joelhos, cotovelos, costas, pulsos).

21 A literatura e a análise do trabalho desenvolvida no setor da logística permitiu compreender o tipo de acidentes mais prevalente neste contexto. De facto, neste setor o trabalho é caracterizado por horários irregulares, constrangimentos físicos, trabalho pouco variado, repetitivo (Droogenbroeck, Vallery, \& Galvan, 2012). É uma atividade sujeita à pressão do cliente (que não é o cliente final, mas as lojas onde o cliente final adquire os produtos) manifesta na necessidade de ter de respeitar prazos de entrega curtos (Davezies, 2016). É ainda um trabalho individual, 'isolado' e com pouca visibilidade, no qual a atividade do preparador de encomendas é dirigida por um sistema informático com dispositivo de comando vocal (voice picking): no processo de preparação de encomendas, o preparador recebe através de um headset a instrução para ir até um determinado ponto do armazém, definido por um código numérico; quando lá chega, comunica ao sistema o código desbloqueador que figura neste local; o sistema 
indica então o número de caixas a retirar da palete ou a depositar no porta paletes (Davezies, 2016).

Complementarmente identificam-se outras características, evidenciadas graças ao discurso dos trabalhadores preparadores de encomendas, acerca desta atividade:

- um trabalho que exige minúcia, seja na colagem das etiquetas nas caixas, seja na atenção a ter que manter 'aos códigos, às caixas, e às quantidades que vêm nas caixas. Temos que ver sempre as descrições. [...]Temos que verificar se trazem o código' (trabalhadora do sexo feminino, 45 anos, 13 de antiguidade); 'cuidado na colagem das etiquetas nas caixas: não se podem trocar e tem que se acertar mesmo no quadradinho. Se não estiver no sítio, a caixa é recusada na passadeira e conta como um erro para a operadora' (trabalhadora do sexo feminino, 32 anos, 14 de antiguidade);

- um trabalho com uma margem de manobra extremamente reduzida, embora visível, por exemplo, nas situações em que se escolhe a ordem de colocação dos produtos na palete, para além do planeamento prescrito, conseguir 'paletes bem feitas', 'paletes não desmaiadas', colocando os produtos mais pesados na base do empilhamento;

- um trabalho por objetivos: 'É um trabalho por médias, tem que se alcançar aqueles objetivos' (trabalhadora do sexo feminino, 32 anos, 14 de antiguidade);

- um trabalho com exigências associadas a cargas pesadas e à necessidade de manter as normas de produção: 'O serviço mais pesado é o picker e há aquelas posições... [...] é difícil mantê-las para dar a produção' (trabalhador do sexo masculino, 46 anos, 13 de antiguidade); 'temos que produzir muito e ser rápidos' (trabalhadora do sexo feminino, 36 anos, 7 de antiguidade);

Este estudo, conduzido a partir da análise de entrevistas a trabalhadores a exercer atividades no mesmo setor e com características semelhantes, participantes do mesmo processo despoletado pela empresa, não realçou diferenças relativamente à idade, antiguidade ou género na reconstrução do percurso profissional.

Todavia, a intervenção conduzida junto destes trabalhadores permitiu identificar obstáculos no processo de regresso ao trabalho, e constituir-se como um mediador junto da empresa na procura de alternativas de funções ajustadas aos trabalhadores, tendo em conta, nomeadamente, o ponto de vista e as expectativas destes, no que diz respeito à vontade de preservação da carreira, dos horários de trabalho, das folgas $\mathrm{e}$ fins de semana, das distâncias casa-trabalho (opções de mobilidade casa-trabalho).

\subsection{0 estudo Regresso ao trabalho após acidente: superar obstáculos}

Quando adotamos um ponto de vista situado a uma outra escala de análise, mais macro, considerando diferentes contextos de atividade profissional, observamos que as diferenças de género são suscetíveis de contrastar os percursos profissionais conferindo um outro olhar, mais específico, aos obstáculos que no ponto seguinte serão abordados.

No âmbito do estudo Regresso ao trabalho após acidente: superar obstáculos (Cunha, Santos \& Pereira, 2017), um dos objetivos foi o rastreio dos impactos trazidos pelo acidente para as vertentes profissional, pessoal e familiar do sinistrado, sem as dissociar entre si e sem valorizar apenas a dimensão laboral. 

Trabalho (ANDST), e financiado pelo Instituto Nacional para a Reabilitação, I. P., contemplou uma amostra de 371 participantes, dos quais 287 homens e 84 mulheres. A metodologia utilizada conciliou uma abordagem qualitativa e quantitativa: foram realizadas 10 entrevistas individuais para exploração e reconstrução do percurso póssinistro; e construído um questionário entregue e preenchido por todos os participantes, sócios e ex-sócios da ANDST.

Fazendo uma caracterização mais detalhada da amostra, verifica-se que $71,3 \%$ dos participantes encontra-se no grupo etário que compreende o intervalo entre os 45 e os 54 anos, e $30,2 \%$ o intervalo entre os 35 e 44 anos. Maior percentagem de mulheres com idades entre os 45 e 54 anos aquando do acidente (39,4\%), face a $31,9 \%$ de homens. Relativamente à antiguidade na empresa, $78,1 \%$ da amostra tinha uma antiguidade entre 1 a 10 anos aquando do acidente, seguido de $61,8 \%$ com antiguidade entre 11 e 20 anos. Maior percentagem de mulheres com antiguidade superior a 21 anos (27\%, face a $20,4 \%$ dos homens).

No que respeita à atividade de trabalho exercida aquando do acidente, verificou-se uma maior percentagem de homens na Construção civil (21\%), nos Transportes e Armazenagem $(24,7 \%)$ e nas Indústrias Transformadoras (17,2\%); e maior percentagem de mulheres em atividades de Saúde e Apoio Social (21,2\%), na Indústria Transformadora (15,4\%), e no Trabalho Doméstico (15,4\%).

Esta distribuição por atividade de trabalho acaba por ser consentânea com o tipo de acidente e de lesão retratados [1]: no caso dos homens, os acidentes são sobretudo relacionados com perda de controlo de máquina, manuseamento de ferramentas, meios de transportes (46,7\%); no caso das mulheres, são relatados acidentes relacionados com escorregamento, quedas (38\%) e movimentos do corpo sujeito a constrangimento físico (25,3\%).

\section{Regresso ao trabalho sim, mas com que obstáculos?}

31 Quem regressa ao trabalho na mesma empresa após o acidente? De acordo com os dados do estudo Regresso ao trabalho após acidente: superar obstáculos, não há diferenças notórias neste regresso no caso de homens e mulheres $(80,1 \%$ dos participantes da amostra masculina e $85,9 \%$ da amostra feminina). Do ponto de vista da idade e da antiguidade observamos outra tendência: são os mais velhos e com maior antiguidade quem mais regressa à mesma empresa (percentagens superiores a $80 \%$ em trabalhadores com mais de 45 anos e também superiores a 80\% com mais de 10 anos de antiguidade, face a apenas $41 \%$ no caso dos que tem antiguidade inferior a 1 ano).

Estes resultados são coerentes com os resultados obtidos no estudo de Durand, Baril, Loisel e Gervais (2008), cuja categorização agora retomamos para enfatizar em particular as trajetórias pós-acidente marcadas pelo regresso ao trabalho com obstáculos. Fundamentadas pelo recurso ao que os dois estudos apresentados anteriormente deram a ver, podemos identificar quatro cenários de obstáculos, como a seguir identificamos. 


\subsection{Quando o regresso se faz à mesma função, sem uma análise e planeamento prévios}

Um dos obstáculos que se pode identificar no regresso ao trabalho após acidente é quando o regresso é feito à mesma função, sem uma análise e planeamento prévio deste, por parte de atores-chave (e.g. chefias, recursos humanos, ....).

A inexistência destas práticas pode ser evidenciada com os resultados obtidos no estudo Regresso ao trabalho após acidente: superar obstáculos. Observando a figura 2, verificamos que mais de metade dos participantes regressaram ao trabalho $(77,9 \%)$, permaneceram na mesma empresa ( $74 \%$, dos quais $72 \%$ de homens e $79 \%$ de mulheres) e mantiveram a mesma função (56,6\%, dos quais $56 \%$ homens e $58 \%$ mulheres). No entanto, apenas $8,8 \%$ dos participantes que permaneceram na mesma empresa tiveram o seu posto ou horário de trabalho adaptados, sendo uma modificação mais presente no caso das mulheres ( $12,8 \%$ das mulheres face a $8,7 \%$ dos homens).

Figura 2: Condições de emprego e de trabalho após o acidente, por género.

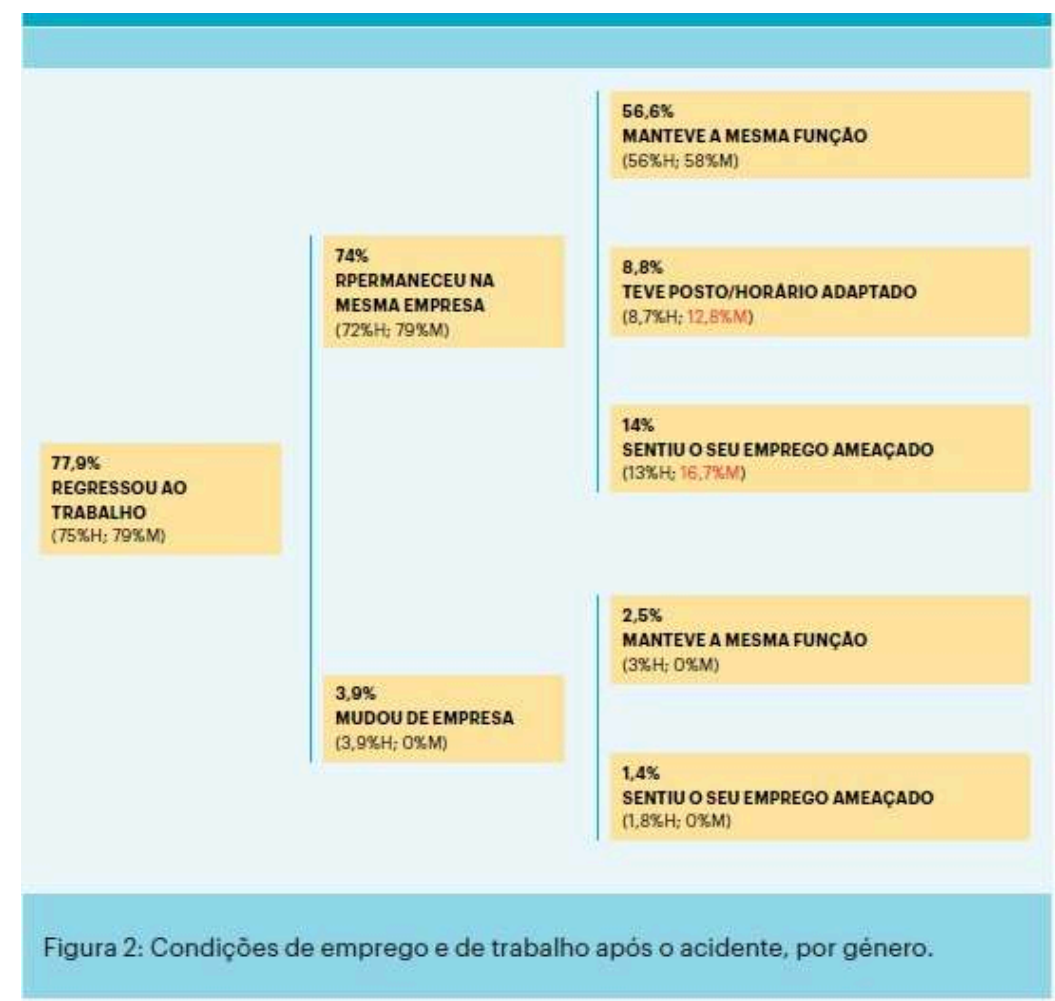

Contudo, são também as mulheres que sentem maior ameaça relativamente à preservação do emprego ( $16,7 \%$, face a $13 \%$ dos homens).

No caso do estudo realizado no setor da logística, verificámos também a existência de indicadores que ajudam a caracterizar o obstáculo relativo à ausência de um processo de reintegração formalizado. Após o período de ausência por acidente de trabalho, as chefias não eram necessariamente informadas sobre o regresso do trabalhador, fazendo a atribuição das tarefas em função das necessidades e disponibilidades avaliadas naquele momento. Neste processo, pelo teor das tarefas a realizar - e atribuídas pelas chefias - só em algumas situações se verificou que eram compatíveis com a restrição médica definida. 
37 Face a este cenário de não ajuste do posto de trabalho, da ausência de um processo de reintegração após o acidente, os trabalhadores acabam por ter de se adaptar: adaptar às tarefas que lhes são atribuídas no momento do regresso, adaptar à realização da mesma atividade (por vezes não compatível com a lesão), desenvolvendo estratégias que lhes permitam voltar a sentir-se úteis no trabalho que realizam. Verificamos no discurso da maioria dos trabalhadores uma lógica de 'querer sentir-se útil no trabalho' e contribuir para o sucesso da equipa, do trabalho, da empresa.

Apesar de não se ter verificado, em nenhum dos dois estudos, estratégias instituídas de reintegração no pós-acidente, que promovessem um regresso sem obstáculos, considera-se que, no caso do estudo do setor da logística, a intervenção iniciada, e promovida pela empresa, relativa à identificação de uma função alternativa, em coerência com o tipo de restrição médica identificada pelo médico de trabalho da empresa, foi um aspeto positivo para estes trabalhadores. O projeto assumiu-se como uma 'esperança' renovada para alguns trabalhadores, de poderem realizar outras tarefas, de sentirem-se novamente úteis no trabalho e na empresa, com a perspetiva de realizar uma atividade que fosse ao encontro das suas competências, interesses, e que fosse também compatível com a sua restrição médica.

39 É preciso, ainda assim, indagar de forma mais global, isto é, ultrapassando o caso singular desta empresa, as condições em que o trabalho passa a ser realizado após o acidente. $\mathrm{O}$ facto de o trabalho anterior ser mantido, ou de ser atribuída uma outra função, mais compatível com a restrição médica adquirida, traz associada uma melhoria das condições em que o trabalho é realizado?

\subsection{Quando o conteúdo do trabalho atribuído não é objeto de debate com os próprios trabalhadores}

Orientando agora a análise para as condições de trabalho a que passam a estar expostos os trabalhadores no seu regresso ao trabalho após o acidente, percebe-se que o acidente surge como um turning point apenas para o sinistrado. A sua realidade de trabalho, mesmo quando este regressa ao trabalho anterior, não é repensada, reforçando-se o princípio de que a 'adaptação' ao posto de trabalho terá que ser desígnio do próprio sinistrado.

41 Após o acidente, as características do trabalho mudam, reforçando o sentimento de dupla penalização - por se ter sofrido o acidente, e por se ter um cenário mais desfavorável de trabalho a partir daí e num horizonte temporal sem termo antecipável. Como podemos ver pelos resultados apresentados na figura 3, o trabalho é muito mais solitário (com um aumento de cerca de $70 \%$ - de $14,1 \%$ para $81,8 \%$, no caso dos homens, e de $10,7 \%$ para $84,9 \%$, no caso das mulheres) com impacto na dimensão coletiva do trabalho, como veremos no ponto seguinte; é mais monótono (aumento em cerca de 2 vezes mais - de $10,3 \%$ para $17,7 \%$, no caso dos homens, e de $12,5 \%$ para $20,8 \%$, no caso das mulheres); e reduzida a possibilidade de aprender coisas novas (diferença mais assinalada no caso das mulheres - de $39,3 \%$ para $22,6 \%$; e de $28,6 \%$ para $11,3 \%$, respetivamente). 
Figura 3: Mudanças na perceção sobre as características do trabalho antes e após acidente, em função do género.

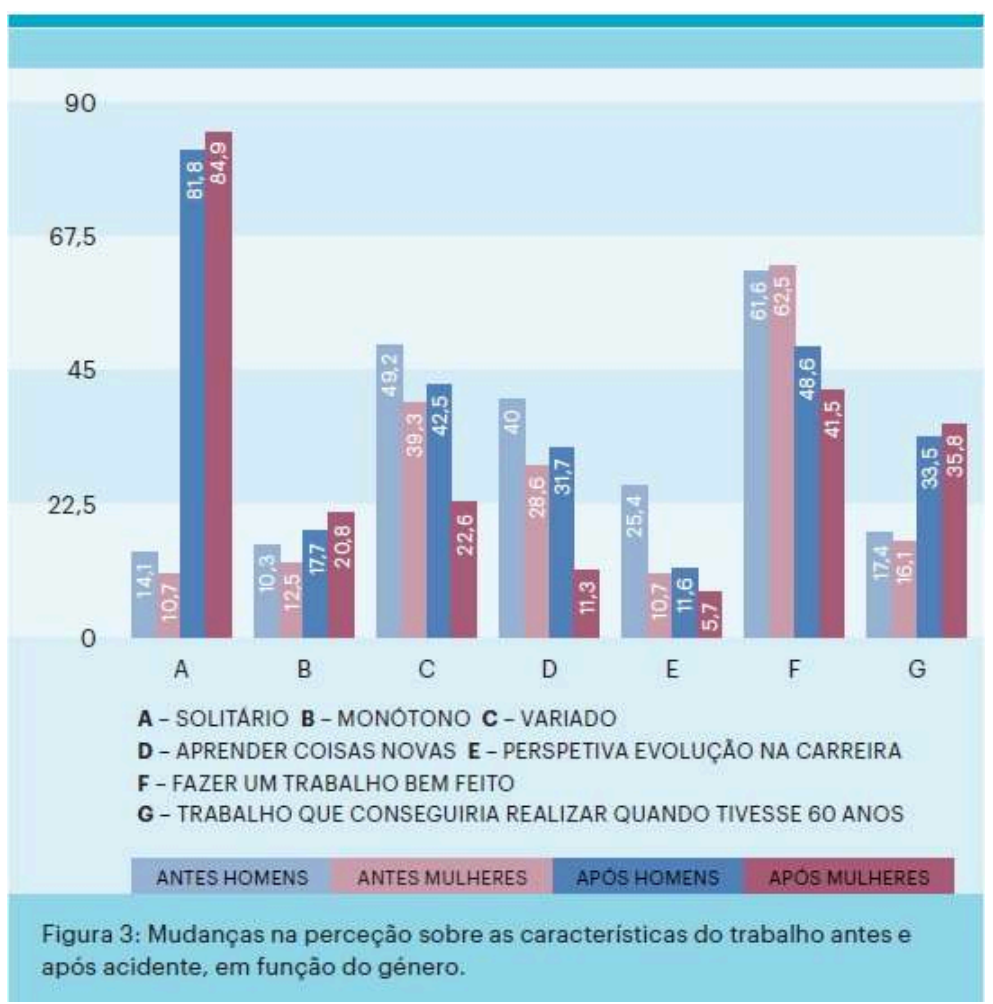

42 Antes do acidente, constata-se a perceção de um trabalho variado, e que permitia aprender coisas novas, tanto para homens como para mulheres ( $49 \%$ dos homens e $39,3 \%$ das mulheres, e $40 \%$ dos homens e $28,6 \%$ das mulheres, respetivamente), ainda que sejam condições mais presentes no caso dos homens ( $49,2 \%$ e $40 \%$, respetivamente). O obstáculo que aqui se enuncia é o facto de o tipo de trabalho a realizar e as condições do seu exercício não serem debatidas com o trabalhador sinistrado, nem realizada qualquer avaliação intermédia, por parte da empresa, do processo de reintegração.

Quando questionámos os trabalhadores do estudo Regresso ao trabalho após acidente: superar obstáculos sobre o seu julgamento acerca das mudanças no trabalho realizado antes e após o acidente, voltamos a encontrar diferenças, de forma global, e também contrastadas pela dimensão género. No momento antes do acidente, cerca de $62 \%$ dos homens e das mulheres consideravam que tinham possibilidade de fazer um trabalho bem feito; após o acidente, esta perceção diminui para $48,6 \%$ dos homens, e $41,5 \%$ das mulheres. De realçar o item relativo à perceção de 'ter um trabalho que conseguiria realizar aos 60 anos', que reúne percentagens mais elevadas após o acidente do que antes do acidente (33,5\% dos homens declaram-no, face a $35,8 \%$ das mulheres). 0 relato sobre a perceção de conseguir realizar o trabalho aos 60 anos, cremos associado, neste caso, a um julgamento de 'capacidade', como se esta perceção fosse preditiva, ou traduzisse a afirmação de que se manterão capazes de realizar o trabalho atual nessa idade.

Após o acidente, o julgamento dos outros sobre o trabalho a realizar ou realizado é ainda mais penalizador. Em alguns casos, é desvalorizada a capacidade de retomar o trabalho anterior, porque mantidos os mesmos padrões de avaliação do desempenho, o que justifica a atribuição de funções percebidas como configuradoras de uma 
'despromoção' (e.g. trabalho no mesmo contexto onde ocorreu o acidente, mas em lugar de se assumir as funções de operador especializado, passa a assumir tarefas mais indiferenciadas e tidas como mais leves, frequentemente, tarefas de limpeza e de reciclagem). Noutros casos, o trabalho realizado não é reconhecido, nomeadamente, quando as funções atribuídas são perspetivadas como funções a extinguir, sob o argumento de que a sua necessidade é uma 'não conformidade' a evitar. São tarefas associadas à gestão de traços da atividade, tidos como 'falhas', 'erros', como é o caso, por exemplo, das tarefas de triagem de 'quebras' resultantes da atividade.

Este obstáculo, referente à ausência de apelo ao ponto de vista do trabalhador sobre o trabalho a realizar após o acidente e sobre as condições em que este passa a ser realizado, é reforçado pelo silêncio que assume na continuidade deste processo. Silêncio do ponto de vista individual, nomeadamente na declaração de dores que persistem no tempo (mais comuns nas mulheres, até pelo tipo de acidentes que sofrem e cujas lesões são de tipo músculo-esquelético). E silêncio também sobre o recurso a ajuda fora da empresa (e.g. procura de parecer de um outro médico), e sobre eventuais alternativas a ponderar (e.g. pesquisa de outras funções disponíveis). Este silêncio é perpetuado pela conviç̧ão de que uma postura diferente se consubstanciaria mais rapidamente em ameaça de perda do emprego.

\subsection{Quando o regresso é também a um coletivo a quem se impõe uma reorganização}

O regresso ao trabalho após um acidente é feito também pela reintegração num coletivo de trabalho. As condições existentes para que chefias e colegas acolham este trabalhador vão ser, desta forma, determinantes para se qualificar a 'dimensão' deste obstáculo que terá que ser enfrentado. Estas condições relacionam-se, nomeadamente, com a quantidade de tarefas a desempenhar, o tempo e as metas definidas para a realização dessas tarefas, o efetivo previsto para a sua concretização, e a quantidade de trabalhadores com restrição médica já existentes na equipa. De facto, o ponto de vista dos colegas de trabalho, mesmo quando compreendem bem as circunstâncias em que a restrição de um colega foi adquirida, vai ser atravessado pelo desafio de fazer face às metas impostas, com um (ou mais colegas) que não podem realizar todas as tarefas previstas - aumentando, desta forma, a carga de trabalho da equipa -, e ainda pela necessidade de interromper a realização do seu trabalho para o(s) ajudar em alguns momentos. O trabalhador acidentado não fica incólume face a esta situação. São frequentes os relatos em que os trabalhadores referem sentir-se um 'fardo' para a equipa, recorrendo a diferentes estratégias para não penalizar os colegas, mas garantindo a sua colaboração: por exemplo, não recorrem sempre ao mesmo colega; pedem ajuda com recurso ao humor e reconhecendo as suas limitações; ou escolhem os momentos que consideram importunar menos.

Ora, esta dificuldade/impossibilidade de realizar algumas das tarefas, nomeadamente aquelas mais penosas, mesmo quando há indicação médica explícita nesse sentido, acaba por ter consequências na forma como as chefias avaliam o trabalho desempenhado. Numa fase em que ainda não foi encontrado um novo posto, ou adequado o atual, as tarefas desempenhadas pelo trabalhador acidentado parecem estar aquém das que são desenvolvidas pelos seus colegas (ou das que eram desenvolvidas por si antes do acidente), pelo que, na hora de decidir sobre a atribuição de um prémio 
de produtividade, está sempre presente esta comparação. Sem uma indicação formal sobre a forma de ponderar nestes casos, cada chefia vai decidir se o corte do prémio é total ou parcial, se a sua decisão permanece constante ou se está, 'apesar de tudo', relacionado com o desempenho em cada momento.

Estas questões também podem ser observadas a partir dos dados estatísticos recolhidos (figura 4). Com efeito, estes mostram que no momento antes do acidente, a perceção dos trabalhadores é a de que podiam contar com ajuda e cooperação por parte dos colegas ( $48,1 \%$ dos homens, face a $39,3 \%$ das mulheres) e das chefias ( $36,8 \%$ dos homens, face a $23,6 \%$ das mulheres), e tinham o reconhecimento do seu trabalho por parte dos colegas ( $48,1 \%$ dos homens, face a $35,7 \%$ das mulheres) e chefias $(39,5 \%$ dos homens, face a $32,7 \%$ das mulheres). Contudo, após o acidente, observa-se uma diminuição das percentagens em todos os itens, salientando-se, sobretudo a ajuda e cooperação das chefias ( $29,3 \%$ no caso dos homens, face a $13,2 \%$ no das mulheres) e o reconhecimento do trabalho pelas chefias ( $31,5 \%$ dos homens, face a $19,2 \%$ das mulheres).

Figura 4: Mudanças na perceção sobre o coletivo de trabalho antes e após acidente, em função do género.

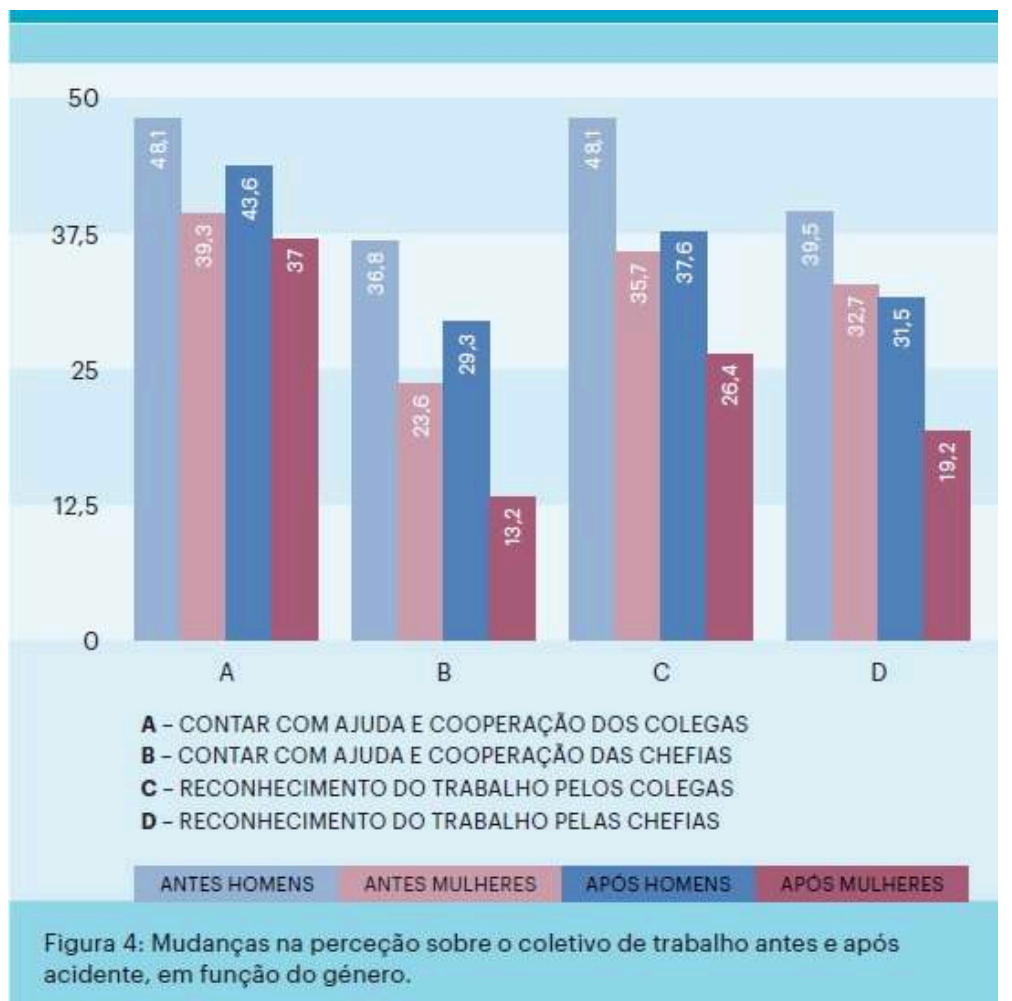

Não poder contar tanto com a ajuda de colegas e chefias e, sobretudo, não ter o mesmo reconhecimento pelo trabalho realizado, participa, na linha de alguns autores (Clot, 1999, Dejours, 2003), na perca da função psicológica do trabalho contribuindo, em algumas situações, para o adoecimento dos trabalhadores.

Torna-se assim evidente que repensar o trabalho após o acidente não implica apenas adequar o posto, as tarefas e as ferramentas de trabalho. Implica criar condições para se realizar um trabalho bem feito no seio de um coletivo de trabalho, que não pode sair penalizado por integrar um colega com restrições médicas. 


\section{Conclusão}

51 Se o regresso ao trabalho após o acidente é tido pelos trabalhadores como prova de que foram as condições de trabalho que determinaram a ocorrência do acidente, de outro modo a presunção de culpa e o 'infortúnio' seria acometido a cada um; o percurso póssinistro é o início de um processo renovado de constrangimentos e de dificuldades, a que se veem confrontados estes trabalhadores. De facto, nestes dois estudos desenvolvidos em Portugal não encontramos percursos pós-acidente em que houve retorno ao trabalho sem qualquer obstáculo.

Assim, tendo como referência o estudo de Durand, Baril, Loisel \& Gervais (2008) as categorias da modelização proposta no que diz respeito a percursos pós-acidente embora sejam igualmente possíveis, têm uma prevalência distinta nos nossos estudos, com enfâse particular no quadrante 'regresso ao trabalho com obstáculos'. Entre estes obstáculos identificou-se a ausência de planeamento e reestruturação do posto de trabalho; ausência de consideração do ponto de vista do trabalhador sobre o conteúdo do trabalho atribuído; ausência de margem de manobra deixada ao coletivo de trabalho, tendo em vista a sua reorganização.

Apesar de tudo, a análise do caso da empresa específica considerada, que formulou um pedido de intervenção no sentido do apoio na reorientação profissional dos trabalhadores sinistrados após o seu regresso à empresa, é reveladora de uma outra atenção a estas situações. No caso dos trabalhadores do estudo Regresso ao trabalho após acidente: superar obstáculos, essa ajuda não proveio da empresa, mas também não estiveram sós, procuraram e obtiveram ajuda junto da ANDST. Foi, aliás, só com sócios e ex-sócios desta Associação que este segundo estudo foi prosseguido. Trata-se, diremos, de uma limitação do próprio estudo, mas tal é revelador de outras desigualdades de género: há mais homens do que mulheres sócios, e uma experiência diferenciada dos atores desta instituição na análise de situações concretas de acidente e de apoio na reivindicação dos direitos das mulheres vítimas de acidentes. E, se as diferenças identificadas neste estudo ganham expressão face ao que nos dá a ver o que se passa no caso de uma empresa singular, coloca-se em debate e reforça-se a importância de introdução desta dimensão de género na análise mais global dos acidentes de trabalho, e na divulgação regular dos dados oficiais pelas instituições responsáveis.

\section{BIBLIOGRAFIA}

Baril, R., Martin, J.-C., Lapointe, C., \& Massicotte, P. (1994). Étude exploratoire des processus de réinsertion sociale et professionnelle des travailleurs en réadaptation. Québec: IRSST.

Clot, Y. (1999). La fonction psychologique du travail. Paris: PUF.

Cunha, L., Santos, M., \& Pereira, C. (2017). Return to employment after a work-related accident: how he/she defines himself/herself in relation to others. ETUI Seminar: His and Hers occupational hazards, health, justice and prevention actors. ITUH, Brussels, Belgium. 
Davezies, Ph. (2016). Une palette de troubles de santé. Santé \& Travail, 94, 29-31.

Dejours, C. (1995). Le facteur humain. Paris: Presses Universitaires de France (PUF).

Dejours, C. (2003). L'évaluation du travail à l'épreuve du réel. Critique des fondements de l'évaluation. Paris: Éditions Quae.

Delgoulet, C., Cuvelier, L., Gaudart, C., Molinié, A.F., \& Volkoff, S. (2014). Santé et formes de fragilisation dans le travail: construction d'une recherché-intervention. Actes du 49ème Congrès International Société d'Ergonomie de Langue Française.

Droogenbroeck, A. V., Vallery, G., \& Galvan, S. (2012). Le processus d'usure professionnelle dans la grande distribution: effets des conditions de travail et des itinéraires professionnels. 47ème congrès international. Société d'ergonomie de langue française.

Durand, M.-J., Baril, R., Loisel, P., \& Gervais, J. (2008). Trajectoires des travailleurs recevant un programme de retour au travail: étude exploratoire des discussions d'une équipe interdisciplinaire. Perspectives interdisciplinaires sur le travail et la santé [En ligne], 10-2 | 2008, mis en ligne le 01 novembre 2008, consulté le 23 février 2018. URL: http:// journals.openedition.org/pistes/2223 ; DOI: 10.4000/pistes.2223

Hareven, T. \& Masaoka, K. (1988). Turning points and transitions: perceptions of the life course. Journal of Family History, 13, 3, 271-289. https://doi.org/10.1177/036319908801300117

Hélardot, V. (2009). Vouloir ce qui arrive? Les bifurcations biographiques entre logiques structurelles et choix individuels. In Michel Grossetti et al., Bifurcations (p.160-167). La Découverte «Recherches».

Ramos, S. (2010). Envelhecimento, trabalho e cognição: do laboratório para o terreno na construção de uma alternativa metodológica. Lisboa: Fundação Calouste Gulbenkian.

\section{NOTAS}

1. Pela impossibilidade de análise dos dados relativos à amostra em análise no presente estudo (276 participantes), apresentam-se, de modo ilustrativo, os resultados da amostra total do estudo (371).

\section{RESUMOS}

Este artigo explora obstáculos com os quais os sinistrados do trabalho se deparam no regresso ao trabalho após o acidente. Dois estudos desenvolvidos em Portugal servem de referência à análise e reflexão sobre esta questão. Um dos estudos resultou do pedido de intervenção de uma empresa do Norte de Portugal, junto de trabalhadores com restrição médica para o trabalho habitual, com o objetivo de se definir um contexto alternativo de trabalho; e o outro estudo, solicitado pela Associação Nacional dos Deficientes e Sinistrados do Trabalho, visou a construção de um retrato dos percursos pós-acidente de trabalhadores de diferentes setores de atividade.

Os resultados permitiram sistematizar três grandes categorias de obstáculos, designadamente, quando o regresso é feito à mesma função, mas sem uma análise e planeamento prévios; quando o 
conteúdo do trabalho atribuído não é objeto de debate com os trabalhadores; e quando o regresso é feito sem ter em conta o facto de haver necessidade também de o coletivo de trabalho se reorganizar.

Reforça-se a conceção do acidente de trabalho como um turning point no percurso profissional, com implicações sempre singulares, cuja análise permite ainda sinalizar propostas de intervenção concretas para além dos percursos individuais.

Este artículo explora los obstáculos que los accidentados del trabajo enfrentan cuando vuelven al trabajo tras un accidente. Dos estudios realizados en Portugal sirven de referencia para el análisis y reflexión sobre este tema. Uno de los estudios tuvo origen en la solicitud de intervención de una empresa en el norte de Portugal y se centró en los trabajadores con restricciones médicas para el trabajo habitual a fin de definir un entorno de trabajo alternativo; el otro estudio, solicitado por la Associação Nacional dos Deficientes e Sinistrados do Trabalho[Asociación Nacional de Discapacitados y Accidentados del Trabajo], tuvo como objetivo elaborar un perfil de las trayectorias post-accidente de trabajadores de diferentes sectores de actividad. Los resultados permitieron sistematizar tres grandes categorías de obstáculos, en particular, cuando se vuelve a la misma función, pero sin un análisis ni una planificación previos; cuando el contenido del trabajo asignado no se debate con los trabajadores; y cuando la vuelta se hace sin tener en cuenta el hecho de que también es necesario que el colectivo de trabajo se reorganice. Se refuerza la noción del accidente de trabajo como un turning point en la trayectoria profesional, con consecuencias siempre singulares, cuyo análisis permite aún identificar propuestas de intervención concretas más allá de las trayectorias individuales.

Cet article cherche à explorer les obstacles auxquels sont confrontés les accidentés du travail lors de leur retour à l'activité professionnelle. Deux études menées au Portugal servent de référence à l'analyse et à la réflexion concernant cette question. La première étude a été mise en place à la demande d'une entreprise du Nord du Portugal qui souhaitait une intervention auprès de travailleurs souffrant d'une incapacité partielle de travail, afin de définir un contexte alternatif de travail. La seconde étude, sollicitée par l'Associação Nacional dos Deficientes e Sinistrados do Trabalho [Association Nationale des Handicapés et Sinistrés du Travail], cherchait à dresser un profil des parcours post-accident de travailleurs issus de différents secteurs d'activité.

Les résultats ont permis de systématiser trois grandes catégories d'obstacles: lorsque le retour se fait au même poste mais sans analyse et planification préalables ; lorsque le contenu du travail attribué ne fait pas l'objet de débat avec les travailleurs ; lorsque le retour se fait sans tenir compte de la nécessité de réorganisation du collectif de travailleurs.

La conception de l'accident du travail en tant que moment charnière (turning point) dans le parcours professionnel s'est trouvé renforcée par cette étude. Bien que les conséquences soient toujours singulières, l'analyse a permis de mettre en évidence des propositions d'intervention concrètes qui se situent au-delà des parcours individuels.

This paper discusses the obstacles the injured workers have to face upon their return to work after the accident. Two studies developed in Portugal support the analysis and the reflection on this issue. One of the studies is the outcome of a request from a company settled in the North of Portugal involving the workers with medical restrains to perform their usual work. The order consisted in an intervention to define an alternative work context. The other study, ordered by the Associação Nacional dos Deficientes e Sinistrados do Trabalho [National Association of Disabled Workers Injured On-the-job], aimed at depicting the workers' post-accident paths from different activity sectors.

Three main categories of obstacles emerge from the findings, namely, when the workers return to the same function with no prior analysis and planning; when the content of the job is assigned without taking the workers' opinion into account; and when the return neglects the need for the 
collective work to be reorganized.

The concept of the work accident as a turning point in the professional path is reinforced. The implications are always unique and the analysis to that singularity makes it possible to sign specific intervention proposals beyond the individual paths.

ÍNDICE

Mots-clés: accident de travail, turning point, trajectoires, obstacles

Palavras-chave: acidentes de trabalho, turning point, percursos, obstáculos

Keywords: work accidents, turning point, paths, obstacles

Palabras claves: accidentes de trabajo, turning point, trayectorias, obstáculos

\section{AUTORES}

\section{CLÁUDIA PEREIRA}

Faculdade de Psicologia e de Ciências da Educação Universidade do Porto Rua Alfredo Allen 4200-135 Porto Portugal

cpereira@fpce.up.pt

\section{MARTA SANTOS}

Centro de Psicologia da Universidade do Porto Faculdade de Psicologia e de Ciências da Educação Universidade do Porto Rua Alfredo Allen 4200-135 Porto Portugal marta@fpce.up.pt

\section{LILIANA CUNHA}

Centro de Psicologia da Universidade do Porto Faculdade de Psicologia e de Ciências da Educação Universidade do Porto Rua Alfredo Allen 4200-135 Porto Portugal

lcunha@fpce.up.pt 